1,700 crossings in Britain, and naturally the installation of all these crossings is costly. The second step in advance was the introduction of the vehicleactuated method of control, which has several advantages over the time-controlled system. With the time-controlled apparatus the 'right of way' is given to each of two or more intersecting roads for definite periods of time in sequence, quite regardless of the relative volume of traffic on the roads at any particular moment. One of the essentials of any form of control is to keep traffic moving, and this should only be subordinate to safety. The timecontrolled system is powerless to differentiate between the volumes of the flow of traffic in the various directions. Many attempts were made in the past to produce a system which would provide maximum traffic facilities with maximum safety. There are now two systems of vehicle-activated control in practice, called the electromatic and the autoflex respectively. In the former, a vehicle passing over a pad makes contact and completes an electric circuit; in the latter the air in a channel in a rubber moulding is compressed and the compressed air produces the contact. The problem of co-ordinating a series of crossings is now being satisfactorily solved. Oxford Street, London, from Marble Arch to Tottenham Court Road is a good example of the advantages of this kind of control.

\section{Invention of the Venturi Meter}

Is connexion with an article on "Early Hydraulic Engineering", in which the work of Clemens Herschel (1842-1930) is referred to, Engineering in its issue for August 2 reproduces a letter from Herschel to the late Dr. Unwin describing his invention of the Venturi Meter. The letter is dated June 5, 1888, and addressed from the hydraulic engineer's office of the Holyoke Water Power Co., Mass. In his letter, Herschel says he tested a one-inch Venturi Meter, under $210 \mathrm{ft}$. head: "I am now satisfied that here is a new and pregnant principle to be applied to the art of gauging fluids, inclusive of fluids such as com. pressed air, illuminating or fuel gases, steam, etc. Further, that the shape of the meter should be trumpet-shaped in both directions; such a meter will measure volumes flowing in either direction, which in certain localities becomes a useful attribute. ... And we are but in the beginning of the art of measuring pressures, and differences of pressure. When these shall be delicately measured, the Venturi Meter will have become as delicate in its lower limits of capacity, as any other and it is on this score alone, that it is as yet inferior to some of the volumetric meters." The letter was found among the papers placed at the disposal of the Unwin Memorial Committee by Miss Unwin.

\section{Electric Welding in Industry}

THE American Welding Society has awarded the S. W. Miller Medal to J. C. Lincoln, the founder of the Lincoln Electric Company, as the first to apply the electrical are to building construction, and for his improvements in the art of are welding. Mr.
Lincoln has pointed out that by are welding the cost of the repairs of machines has been greatly reduced. It has eliminated the noise of the riveting hammer in building construction. A joint made by are welding is often stronger than the parent metal; while a joint made by riveting never is. The amount of the material needed for the structure is therefore considerably reduced. It is of particular importance in marine construction, where the smooth outline rendered possible by welding appreciably increases the speed of the ship. The most widely used application of all is the replacement of steel and iron castings by welded structural steel. This application gives a method of having a lighter, stronger and cheaper material than it is possible to get by casting. Already about one and a half million tons of castings a year have been eliminated by this method. Mr. Lincoln thinks that welding will entirely eliminate the rivet as a method of joining structures. It will also largely increase the value of worn and broken parts.

\section{Industrial Physicists}

THE Review of Scientific Instruments reproduces in its issue of February the conclusions of the Conference held in New York to consider "the place of physics in industry and the best methods by which that place can be fully occupied". The Conference demands a training which shall develop : (1) a broad knowledge of the principles of physics with a leaning towards classical physics; (2) an intimate working knowledge of the more elementary branches of mathematics; (3) a grounding in the principles of chemistry sufficient for physical research; (4) power of expression in technical and especially non-technical language; (5) realisation that a research worker in industry is justified only by his value to the industry. It would be of great interest to discover whether these are the demands of industry in Great Britain, and if so, whether the training required is being provided by our educational methods.

\section{Institute of Plant Industry, U.S.S.R.}

A uIst of the publications during 1933 of the Institute of Plant Industry, Leningrad, compiled by Strumillo, appears as Bibliographical Contributions No. 4 of the Institute. The list of publications of this Institute, and of the old Bureau of Applied Botany which preceded it, is thus now complete from 1908 to the end of 1933. It covers 57 publications, is pub. lished in Russian and English, and the titles of all contributions of every volume are given in English even in cases where the originals contain no English summary. Most of the Institute's publications of specialised character have English summaries; those publications in this list which are not provided with one are indicated. The Bulletin of Applied Botany, of Genetics and Plant Breeding, together with its supplements, occupies the major portion of this list. The remainder is occupied by non-serial publications and by publications originating from the Institute, but issued by other publishers. "Plant Industry in the U.S.S.R." and "Agricultural Turkey" are two important contributions in the latter category. 
Indexes arranged according to subjects and to authors are provided. The importance of the work of the Institute of Plant Industry, the extent of its activities, and the diversity of its serial and non-serial publica. tions, make its bibliographical publications indispensable to applied botanists.

\section{Ocean Transportation of Petroleum in Bulk}

OwING to world trade depression and to production problems within the industry, there is now actually available excess oil tanker tonnage over demand. Of the world's steam tanker tonnage 44 per cent is, however, more than fifteen years old, consequently new tankers will shortly have to be constructed to replace these and to meet anticipated increase in demand when trade recovers. Mr. R. F. Hand read a paper on April 5 before the North East Coast Institution of Engineers and Shipbuilders, in which he indicated some of the problems attendant on ocean transportation of petroleum in bulk. Great care must be exercised in allocating vessels for specific work, account being taken of condition, size, position and capability of the tanker to carry the cargo in question. Freights cannot be imposed on a basis of cost plus a reasonable margin of profit, but must be fixed at a rate which the traffic can bear. Ultimate profit must be envisaged over a number of years, and provision made for periods when goods may actually have to be carried at a loss. A classification is suggested for petroleum products from the point of view of marine transport and types of vessel most suitable for carrying the various grades indicated. Operating costs are difficult to assess at the present time owing to the complex foreign exchange situation; but such data as are available prove that though the motor tanker is more economical for long hauls it is not always so in the case of short hauls.

\section{The Science Museum}

According to the Report of the Science Museum for the year 1934 (London: H.M. Stationery Office, $1935,1 s$. net) well over a million visitors have made use of the Museum, including more than a thousand organised groups and parties of about thirty, and the attendances at lectures were well over 30,000. The policy of holding special exhibitions to illustrate the advance of science into industry has been most successful, and the attendance at those on refrigeration from April until September 1934 and on rubber from November 1934 until April 1935 was very gratifying. 'The children's gallery has been visited by 13,000 children in school parties, and the introductory collection installed there has proved very attractive. Short accounts are given in the Report of the progress in each of the five divisions: industrial machinery and manufactures, mechanical and civil engineering, air and water transport, mathematics, astronomy and chemistry, physics and geophysics, and it is quite evident that the delay in reconstructing the central block is a serious obstacle in the way of a more instructive display of the material now crowded into inadequate cases. The Science Library now possesses a quarter of a million books, and nearly 50,000 readers have made use of them. The free space for new books is nearly exhausted and temporary housing will have to be provided until the central block becomes available.

\section{Fuel Research Institute of South Africa}

DR. J. G. VoGEL, director of the Fuel Research Institute of South Africa, has recently described the activities of the Institute (S. African J. Sci., 31, 194-209, Nov. 1934). Initially, the Union Government wished to encourage the export trade in coal, and prevent the damaging effect on the export of coal of unreliable grade. Now all coal loaded for export or bunkers must be graded by the Institute before shipment. The programme is determined by the fact that the coal industry is neither very old nor extensive, and the information available is limited. A first step is therefore a chemical survey. Already the Institute has made a notable contribution to the difficult problem of coal sampling by devising a novel sampling device. It consists essentially of a rotary drill working inside a sheath, up which a rapid current of air passes. The air and the coal abraded by the drill are drawn into a container after the manner of a vacuum cleaner, where the solids are retained. This apparatus not only enables samples to be collected from seams, but also from waggons-a problem which has not hitherto received a satisfactory solution. The Institute is equipped for research in coal chemistry and coal processing, and also for the study of liquid and gaseous fuels.

\section{Census Statistics}

THE normal series of publications dealing with the figures of the 1931 census is completed by the issue of General Tables, a volume of some two hundred and fifty pages (London : H.M.S.O. 11s.). It contains tables giving the populations by sex of the constituent regions of England and Wales-counties, boroughs, urban and rural districts-showing the changes that have occurred in recent intercensal periods. It also gives an analysis of the age and marital condition of the population at successive censuses during the last ninety years. Particulars are given of the birth-places and nationalities of the population in regions, boroughs and other urban areas, and comparative figures for England and Wales at successive censuses. There are also figures of population speaking the Welsh language. Much of the information given in the volume has hitherto been obtainable only by laborious extraction from separate county records.

\section{The Imperial Institute}

WE have received the annual report of the Imperial Institute, recently presented by the director, Sir Harry A. F. Lindsay, to the Board of Governors (London: Imperial Institute, 2s.). This gives a general account of the activities of the Institute and details of many special investigations which have been made with Empire products. These comprise work on silk, cordage fibres, tung oil, shellac, hides and leather, oil seeds, tanning materials, drugs and insecticides, 